\title{
Series editors' preface: Evaluating Sustainable Development - topics, trends and target groups of this new book series
}

\section{Peter Hardi and André Martinuzzi}

During the last 25 years, sustainable development has evolved from a vague vision into an internationally accepted conceptual model and even a framework condition influencing strategic decision-making. While evaluating sustainable development is becoming increasingly important in both policymaking and evaluation practice, the disciplines involved (social, economic and environmental sciences), look at it in different ways. There are neither a generally accepted set of measures and evaluation methods, nor standards to follow. Considering the diversity of interpretations of sustainable development and the complexity of the concept we can neither promise nor expect to develop a single set of measures or a one-size-fits-all approach for evaluating sustainable development. We, however, can provide an overview of the different methods and approaches used, show recent trends and highlight some of the most important fields of application.

The objective of this new book series is to provide a bridge between academic and applied research, and present results directly relevant to policymakers. The series will also establish a baseline of practical approaches to evaluating sustainable development, and present the stages of a historical process in the development of the practice, thus providing not only a link between academic research and policy application, but also adequate research material and references for further academic work. Regarding scientific gaps, the new book series addresses the new methodological challenges caused by the concept of sustainable development, facilitates an exchange of experience between various fields of application and disciplines, and aims at capacity building for evaluation.

The volumes will compile selected papers presented at five international conferences (the so-called EASY-ECO series), organized by a consortium of seven European universities and research institutes. This series of events is 
financed by the EU's FP6 Marie Curie programme and sponsored by the United Nations Environment Programme, SkyEurope and a number of local sponsors. UNESCO designated EASY-ECO as a project of the 'Decade of Education for Sustainable Development'.

As an introduction to this new book series, we, the editors of the series, are providing you with a short overview on:

- why evaluating sustainable development is an important topic for researchers and practitioners all over Europe and beyond;

- how the recent state of the art in evaluating sustainable development will be reflected in this book series;

- which target audience we had in mind when we designed this book series;

- how the book series is linked to the EASY-ECO process; and

- which topics will be dealt with in the next volumes.

Editing a book series is an ongoing process and the quality of the whole series depends on the high quality of each individual contribution. Therefore we would like to invite researchers and practitioners to present their findings and share their experiences at any of the EASY-ECO conferences (for more details see www.sustainability.at/easy, for dates see p. xxi) and in our new book series.

\section{WHY EVALUATING SUSTAINABLE DEVELOPMENT IS IMPORTANT FOR RESEARCHERS AND PRACTITIONERS ALL OVER EUROPE AND BEYOND}

The concept of sustainable development is gaining widespread acceptance in Europe. The European Commission and member states are pursuing sustainable development in various policy fields and programmes. Thousands of communities all over Europe (and beyond) are engaged in Local Agenda 21 activities based on local interpretations of sustainable development. Furthermore, major corporations, are paying increasing attention to corporate social responsibility (CSR), a business version of sustainable development. We witness a transition process in which evaluations can support evidencebased decisions and play an important role as a feedback tool.

Governance structures and practices in Europe are about to change, not only on the Community level, but also on the national and the sub-national levels. Against the background of increasingly alienated citizens, the concept of 'good governance' - openness, participation, accountability, effectiveness and coherence - is gaining momentum. Sustainability evaluations support 
every one of these principles, making policies more transparent and accountable.

The enlargement of the European Union from 15 to 25, then 27 member states is a significant development of our time. One of the challenges of the $\mathrm{EU}$ is to promote institutional as well as socio-economic reforms and to strengthen European cohesion. Evaluations may contribute to enhancing the integration of new member states by elucidating success factors and lessons learned.

\section{THE STATE OF THE ART IN EVALUATING SUSTAINABLE DEVELOPMENT}

Evaluating sustainable development implies four challenges for evaluation research and practice, setting the scientific background of our new book series:

- The integration of the economic, social and environmental dimensions of sustainable development requires integrated assessment concepts, which must also take non-monetary and qualitative aspects into account. In order to derive sound judgements, trade-offs between the three dimensions and the conflict between 'weak sustainability' and 'strong sustainability' need to be addressed explicitly.

- The wide temporal and geographical horizon of sustainable development requires integrated system models and reliable monitoring data. In evaluations, the time lags of interventions and system reactions, long-term risks and system dynamics have to be taken into account.

- Institutional innovations are a chance for sustainable development, and sustainability evaluations are a key factor for institutional innovations. For this purpose, evaluations need to be understood as a mutual learning process and the establishment of an adequate institutional culture.

- Sustainability evaluations require stakeholder involvement. In order to cope with this challenge, good evaluators need not only sound scientific but also tacit knowledge and complementary skills. Systemic and participative evaluation concepts offer instruments to take stakeholders into account.

Although well-established scientific communities discuss particular problems in a specific and thorough way, these discussions are often restricted to just a few narrow fields of application and they are quite isolated from each other. 
Since evaluating sustainable development is the subject of a multitude of disciplines, approaches and methods, none of them can handle the challenge individually. The new book series addresses both sustainable development and evaluation research and brings together expertise from various scientific disciplines.

There is a gap between academic and applied research in the field of evaluating sustainable development. This implies that a professional discourse on sustainability evaluations is seriously lacking. The new book series addresses this challenge by providing an interdisciplinary discussion platform for researchers as well as practitioners.

\section{THE TARGET AUDIENCE OF THIS BOOK SERIES}

The target audience of this book series is not limited to the academic world. The series will try to bridge the gap between high-level academic methodologies, practical experience and the needs of evidence-based decision making:

- The book series will support an exchange of experience among leading academics and junior researchers from all over Europe and beyond. Young researchers will get an overview on this new and dynamic field of study and who wish to understand different methodological approaches. Senior researchers will get insights into recent research and evaluation projects.

- Policy-makers, administration staff and clients of evaluation projects on all levels need reliable information on evaluation methods, fields of application and practical experience. The book series will facilitate the diffusion of the most effective evaluation methodologies, help to increase market transparency and offer a critical perspective on evaluation practice.

- Evaluators, evaluation institutes and evaluation societies in Europe are just starting to deal with evaluating sustainable development as a new field of action. The book series will offer methodological and contentoriented contributions to their discussions and support an exchange of experiences.

- NGOs and NPOs are often aiming to establish quality management systems and need information on the effectiveness of the assistance given. The book series will help them establish evaluation as a learning tool. 
Interdisciplinarity is a strength of the entire book series. Since it is intended to show the full range of evaluation approaches (for example ecological evaluation, policy assessment, economic modelling, sociological methods) it will be of interest of researchers and practitioners of various disciplines.

\section{THE BOOK SERIES AS COMPANION TO THE EASY-ECO CONFERENCES AND TRAINING COURSES}

EASY-ECO ${ }^{1}$ is a series of five international conferences and four training courses, all addressing the challenge of evaluating sustainable development. The key objectives of EASY-ECO are to give an overview of the methods applied and to develop them further in an inter-disciplinary discourse. The first EASY-ECO conferences took place in 2002 and 2003 in Vienna (Austria), the second series started in 2005 in Manchester (UK), has been continued in 2006 in Saarbrücken (Germany) and will be finished in 2008 in Vienna.

EASY-ECO aims to build evaluation capacity by training young researchers and evaluators through a number of training courses. These courses started in September 2005 (Bratislava, Slovakia), continued in January 2006 (Szentendre, Hungary), and are scheduled for May 2007 (Brasov, Romania) and September 2007 (Mogilany, Poland).

EASY-ECO aims to become an academic focal point of sustainability evaluations worldwide and to create a close-knit network within Europe. The new book series will support this process and offers a platform for publication not only for high-level academics, but also for promising young researchers.

\section{THE CONTENT OF THE FIRST TWO VOLUMES}

The book series addresses not only methodological aspects but also evaluation practices in various fields of application on all levels.

\section{Sustainable Development in Europe: Concepts, Evaluation and Applications}

The first volume, edited by Uwe Schubert and Eckhard Störmer from the Vienna University of Economics and Business Administration, provides an overview of concepts, frameworks, methods and applications of sustainability 
evaluations. International evaluation experts offer insights on the cuttingedge research on evaluations. Researchers present the first pan-European overview of various fields of application and methodologies of evaluations in the context of sustainable development. Sustainability evaluations are discussed on the international, national, regional and local level of policymaking, and on the project and corporate level. In addition, young researchers present a survey of sustainability evaluations for European countries. The documented applications offer a market overview of the range of practical evaluation studies. Overall, this volume offers a common basis for the further development of research and application regarding sustainability evaluations.

\section{Impact Assessment for Policy Appraisal: Methods and Practice}

The second volume, edited by Colin Kirkpatrick and Clive George from Manchester University, aims to develop greater understanding of how different forms of strategic impact assessment and evaluation can work together as an integrated whole, with the specific aim of strengthening European sustainable development: locally, nationally, across the entire 25member Union, in partnership with other countries, and the EU's contribution to global governance. The expansion of the European Union to embrace its ten new member states, along with new neighbourhood initiatives with other countries to the east and south, and economic partnerships with developing countries, are occurring in parallel with significant new developments in public policy formulation and decision-making. These include greater emphasis on evidence-based decision-making, better governance and governance reform, and the adoption of sustainable development as the overarching objective for public policy. Chapters will discuss theory, practice and specific experience in all areas of strategic impact assessment, particularly those from which lessons may be learned in the wider context.

\section{BEYOND THE FIRST TWO VOLUMES}

The series editors envision further volumes, depending on the interest generated by the first two volumes and the potentially new areas of research in and application of sustainability evaluation. Advanced preparations have been made for a third and a fourth volume. Please note that titles for further volumes in this series are provisional at this stage, and subject to change.

Vol. 3 (with the suggested working title Improving the Quality of Sustainable Development Projects. Practice, Problems and Perspectives), edited by Wolfgang Meyer and Reinhard Stockmann, Center for Evaluation 
at Saarland University, would deal with the project level of sustainability evaluations and bring together problems, solutions, experience and case studies from a great variety of programs and projects:

- Experience in project and programme evaluations

- Evaluation of sustainability in development cooperation

- Monitoring and evaluation systems for sustainable development

- Evaluation of natural resource management

- Stakeholder involvement and sustainable development

- Evaluation of local and regional initiatives for sustainable development

- Evaluation of national strategies, programmes and projects for sustainable development

This volume would focus on the practice of evaluating sustainable development projects and programmes, as well as on the contribution of science to this practical work. The leading questions for this volume are: What is Europe doing to support sustainable development worldwide? What kind of policy and other measures are used to improve the quality of impacts reached by these interventions? What can Europe (especially the CEE countries) learn from globally gained experience, particularly in the context of development aid projects? How can the exchange between science and these practical experiences be improved?

Vol. 4 (with a suggested working title Sustainability Evaluation as a Learning Process: Institutional Challenges and Responses), edited by Reinhard Steurer and Ursula Kopp, Research Institute for Managing Sustainability at the Vienna University of Economics and Business Administration, would focus on the institutional level of evaluating sustainable development. It should address institutional transformation and capacity-building processes against the background of the first years of history of the EU-25 and look forward to the next round of EU enlargement. The following topics could be included:

- Governance, institutional transition and evaluation

- Institutional structures and capacities for evaluation

- New round of enlargement and sustainability evaluations

- Participatory and systemic evaluation approaches

- Anti-corruption policy and evaluation

The series editors envision further volumes, depending on the interest generated by the first volumes and the potentially new areas of research in and application of sustainability evaluation. One of the additional volumes 
could integrate the scientific outcomes of the EASY-ECO series, while we also consider publishing a university textbook based on the best theoretical papers and case studies, a first of its kind in sustainability evaluation, as well as a practitioners' handbook on evaluation methods and fields of application.

At this stage of the scientific and practitioner's discourse there is the need to get an overview of the different methods and approaches used. There will always be a wide variety of subjects, approaches and needs for evaluation. The new book series aims to reflect this diversity.

\section{NOTE}

1. EASY-ECO stands for 'EvAluation of SustainabilitY - European COnferences'. 